\title{
A Real-world Analysis of Treatment Patterns for Cholinesterase Inhibitors and Memantine among Newly-diagnosed Alzheimer's Disease Patients
}

\author{
Nawal Bent-Ennakhil · Florence Coste (D) Lin Xie • \\ Myrlene Sanon Aigbogun · Yuexi Wang · Furaha Kariburyo • \\ Ann Hartry · Onur Baser · Peter Neumann · Howard Fillit
}

Received: February 7, 2017 / Published online: May 15, 2017

(C) The Author(s) 2017. This article is an open access publication

\begin{abstract}
Introduction: Alzheimer's disease $(\mathrm{AD})$ is the most common neurodegenerative form of dementia. Pharmacological therapies for symptomatic treatment, such as acetylcholinesterase inhibitors (AChEIs) and memantine, have been available in the USA since 2000. Over the past decade, few studies have analyzed real-world anti-dementia treatment patterns in the USA. This study evaluated monotherapy AChEIs and memantine treatment patterns among newly diagnosed $\mathrm{AD}$ patients.
\end{abstract}

Enhanced content To view enhanced content for this article go to http://www.medengine.com/Redeem/ 4E18F060616328D6.

Electronic supplementary material The online version of this article (doi:10.1007/s40120-017-0067-7) contains supplementary material, which is available to authorized users.

N. Bent-Ennakhil · F. Coste $(\bowtie)$

Real World Evidence and Epidemiology, Lundbeck

SAS, Issy-Les-Moulineaux, France

e-mail: FLCO@lundbeck.com

L. Xie $\cdot$ Y. Wang $\cdot$ F. Kariburyo

STATinMED Research, Ann Arbor, MI, USA

M. S. Aigbogun

Health Economics and Outcomes Research, Otsuka

Pharmaceutical Development and

Commercialization, Inc., Princeton, NJ, USA
Methods: A retrospective cohort study was conducted using Medicare data and the Minimum Data Set from 2008 to 2012. Patients aged 65-100 years with newly diagnosed AD (ICD-9 code: 331.0) and monotherapy AChEI or memantine treatment initiated after diagnosis were included. Descriptive treatment pattern analyses, including discontinuation and switch, were undertaken. Kaplan-Meier curves were developed to examine the treatment duration.

Results: A total of 9812 newly diagnosed AD patients were identified, with $56.7 \%(n=5567)$ first receiving anti-dementia treatment after the initial AD diagnosis. Among patients initiating monotherapy AChEIs or memantine after AD diagnosis $(N=5200), 51.6 \%$ continued index treatment during the entire follow-up period (mean follow-up: 659.7 days) and $21.7 \%$ discontinued treatment. Of those who initiated monotherapy treatment with an AChEI, 11.1\% received adjunct therapy with memantine. Among patients with $\geq 1$ year of continuous

\section{A. Hartry}

Lundbeck LLC, Deerfield, IL, USA

O. Baser

Department of Surgery, Center for Innovation and

Outcomes Research, Columbia University, New

York, NY, USA

O. Baser

STATinMED Research, New York, NY, USA 
treatment (mean follow-up: 834 days), $75.6 \%$ remained on the index drug, $10.2 \%$ discontinued during the remaining follow-up period, and 9.5\% of the $\mathrm{AD}$ patients initiating AChEIs received adjunct memantine therapy during the remaining follow-up period.

Conclusion: In the USA Medicare population, about $50 \%$ of the patients who initiated treatment with AChEI or memantine after diagnosis continued the index treatment, and more than $20 \%$ discontinued and were untreated afterwards over the observation period. AD patients initiating AChEIs or memantine were more likely to remain on their treatment if they were persistently treated for the first year.

Keywords: Alzheimer's disease; Anti-dementia drug; Real-world analysis; Treatment pattern

\section{INTRODUCTION}

Alzheimer's disease (AD) is the most common type of dementia, accounting for more than $60 \%$ of all cases, and is characterized by gradually declining cognitive and functional abilities [1]. With a prevalence of 5.3 million, AD was the sixth leading cause of death in the USA in 2015 [1]. Among patients aged $\geq 65$ years, AD was the fifth leading cause of death, with a prevalence of 5.1 million in 2015 [2]. Due to the long duration and nature of the disease, the disability-adjusted life years-which measures the burden of diseases by calculating the years lost due to ill health - was estimated to be 339.0 per 100,000 persons for AD in 2010. This ranked as the 12th highest for a disease in the USA [3].

Acetylcholinesterase inhibitors (AChEIs) including donepezil, rivastigmine, and galantamine-have been the first-line

P. Neumann

Tufts Medical Center, Boston, MA, USA

H. Fillit

The Icahn School of Medicine at Mount Sinai,

Mount Sinai Medical Center, New York, USA

H. Fillit

Alzheimer's Drug Discovery Foundation, New York, NY, USA pharmacotherapy for AD since 1997 [4]. It is believed that persistent treatment with these agents is crucial in obtaining clinical benefit [5]. In a meta-analysis of 22 clinical trials with follow-up ranging from 6 weeks to 3 years, the differences in cognitive subscales ranged from 1.5 to 3.9 points in favor of AChEIs compared to a placebo [6]. In another meta-analysis of 29 clinical trials including 10,758 patients from 1966 to 2001, AChEIs were found to significantly improve the Neuropsychiatric Inventory by 1.72 points (95\% confidence interval [CI]: $0.87-2.57$ ), and activities of daily living (ADL) by 0.1 standard deviations (SDs; 95\% CI: $0.00-0.19)$ as compared to a placebo [7]. A multicenter, natural history study of $201 \mathrm{AD}$ patients demonstrated that AchEI use was associated with delays in reaching the functional end point (Blessed Dementia Rating Scale score $\geq 10$ ) and mortality [8]. In general, AChEIs are safe compounds, and side-effects are limited to gastrointestinal symptoms $[9,10]$ but can lead to significant morbidity in patients with advanced disease [10]. Memantine is an $\mathrm{N}$-methyl-D-aspartate (NMDA) receptor antagonist which has been proved to improve cognition and behavior in moderate-to-severe $\mathrm{AD}$ [11]. It has been approved for use in moderate-to-severe dementia by the USA Food and Drug Administration either as a monotherapy or a component in combination with AChEIs [12].

Although the early initiation and persistence of treatment is thought to be important in relieving the clinical symptoms of $\mathrm{AD}$, a substantial number of $\mathrm{AD}$ patients do not receive medication [13]. In a community-based USA trial conducted in 2001, a majority of AD patients $(64.5 \%)$ were reported either by themselves or by their caregivers as not receiving AChEI treatment [14]. Moreover, patients who discontinued a particular treatment because of adverse events or inadequate response are likely to benefit from switching to other therapies [15]. A study using a global function scale to evaluate the efficacy and safety of rivastigmine in $\mathrm{AD}$ patients who had previously failed to respond to donepezil demonstrated that $56.2 \%$ responded to rivastigmine [15]. 
Previous studies assessing AD treatment patterns in the USA using real-world data are scarce and outdated [16-19]. Few studies have been conducted in other geographical regions. Research in the Republic of Ireland [20] found that rates of non-persistence with anti-dementia medications were $30.1 \%$ at 6 months and $43.8 \%$ at 12 months. Another recent study in Germany [21] showed that after 1 year of follow-up, nearly $60 \%$ of patients continued the antidementia treatment.

This study was conducted to provide an updated review of $\mathrm{AD}$ treatment patterns by examining anti-dementia drug use (memantine and AChEI) and establishing the time dynamics of anti-dementia treatment initiation and changes in previously untreated and newly diagnosed AD patients using a USA nationally representative sample from government medical insurance.

\section{METHODS}

\section{Study Design and Data Source}

A retrospective administrative claims analysis of patients newly diagnosed with $\mathrm{AD}$ and who initiated $\mathrm{AD}$ treatment with either AChEI or memantine after diagnosis was undertaken. Medical and pharmacy claims from the Medicare 5\% national sample administrative database and the Minimum Data Set (MDS) from January 2008 through December 2012, the most currently available data when initiating the analysis, were used. Medicare claims data files included hospital inpatient and outpatient, Medicare carrier, Part D drug events, skilled nursing facility, home health agency, hospice, durable medical equipment, and Medicare denominator files. MDS is a federally mandated nursing home patient assessment instrument. Its files were linked to Medicare data for nursing home residents and were used to capture clinical characteristics for AD patients admitted to a nursing home facility. Patients included in the treatment pattern analysis could live in a nursing home or community setting during the study period.

\section{Patient Selection}

In compliance with ethics guidelines, this article does not contain any new studies with human or animal subjects performed by any of the authors. Since the core study proposed herein was for research purpose only and did not include any individual identifiable data, institutional review board (IRB) exemption was approved for this study. The security of the data meets the requirements of the Health Insurance Portability and Accountability Act (HIPAA) of 1996.

Patients were identified if they were aged 65-100 years with diagnosis claims for AD (International Classification of Diseases, 9th Revision, Clinical Modification [ICD-9-CM] code 331.0) during the identification period (01JAN2009-30JUN2012) and the first AD diagnosis claim date was designated as the index date. Patients were required to have an additional diagnosis claim for $\mathrm{AD}$ or a prescription claim for an anti-dementia drug (donepezil, rivastigmine, galantamine, memantine) after index $\mathrm{AD}$ diagnosis. Each patient was required to have continuous health plan enrollment with medical and pharmacy benefits for at least 12 months pre-index date (baseline period) and 6 months post-index date. Patient data were assessed until the earliest of death, health plan disenrollment, or end of the study period (follow-up period; Fig. 1).

For the purpose of identifying only patients newly diagnosed with $\mathrm{AD}$, those diagnosed with $\mathrm{AD}$ or other AD-related dementia (ICD-9: 290.xx, 294.xx, 331.1, 331.2, 331.7, 331.82, $331.89,331.9,797)$ during the baseline period and patients prescribed anti-dementia medication during the baseline period were excluded from the study.

Patients were categorized as treated or untreated based on the dementia treatment (donepezil, rivastigmine, galantamine, and memantine) received after the first $\mathrm{AD}$ diagnosis date. Patients who initiated AD treatment with combination therapies were defined as having a second anti-dementia drug with a $\geq 14$-day overlap with their first anti-dementia prescription and having a second fill for both 


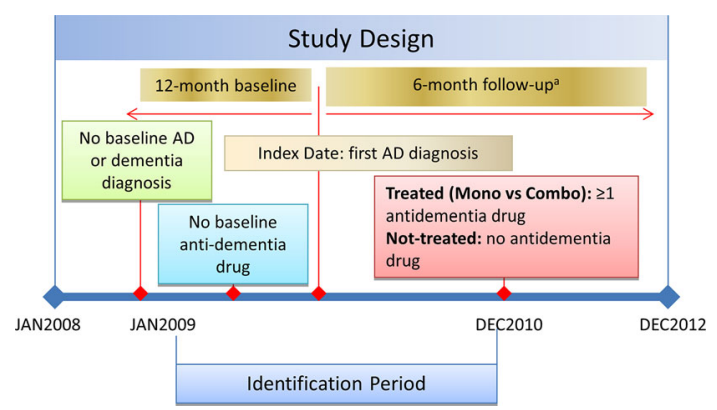

Fig. 1 Study design figure. $A D$ Alzheimer's disease. ${ }^{2}$ Patient data were assessed until the earliest of death, disenrollment, or end of study period

components. To evaluate mainstream treatment for $\mathrm{AD}$, the study focused on patients who initiated $\mathrm{AD}$ treatment with monotherapy after their first AD diagnosis. Therefore, those who initiated treatment with combination therapies were not included in the treatment pattern analysis.

\section{Study Measures}

\section{Baseline Variables}

Baseline socio-demographic and clinical characteristics were examined during 12 months prior to index AD diagnosis. Variables included age, race, gender, geographic location, and Charlson Comorbidity Index (CCI) score. Comorbidities and concomitant medications were also assessed during the baseline period.

For patients residing in a nursing home with linked MDS data, AD-related severity indices were examined, including the Cognitive Performance Scale (CPS) and Activities of Daily Living (ADL) scale. The CPS is designed to assess the cognitive status of a nursing home resident. The CPS has five components that address cognitive and communication domains: memory, decision-making, making self understood, presence of coma, and eating dependency. CPS scores range from 0 (intact) to 6 (very severe impairment) [22]. The ADL scale measures the activities of daily living or tasks related to personal care of residents in the nursing home. The ADL short form (ADL-SF) evaluates the capability of the resident on four items (eating, personal hygiene, toileting, and locomotion) and evaluates what the resident actually did.
The ADL-SF sums the individual ADL items (rating of 0 to 4 , with 0 indicating full independence and 4 indicating complete dependence) into a scale ranging from 0 to 16 [23].

\section{Treatment Patterns}

Treatment patterns were classified into four mutually exclusive categories: switch, discontinuation, retreatment, and ongoing. The index treatment run-out date was defined as the prescription fill date plus the number of days' supply of the index drug without another fill in 45 days. Patients were included in the switch group if they had a prescription of a different $\mathrm{AD}$ treatment before the run-out date of the index drug or within 45 days after the run-out date of index drug. Patients who had an adjunct therapy were also captured in this switch group, defined as patients who were prescribed AChEI and memantine concomitantly for $\geq 14$ days with a second refill for both of the components. Discontinuation was defined as patients who had no additional prescription for any $\mathrm{AD}$ treatment after the index medication run-out date and did not switch to other $\mathrm{AD}$ treatment before the run-out date. Retreatment was defined as patients who did not have a switch but had any delayed AD treatment after 45 days of run-out date of index drug and the drugs for retreatment could be the same or different from their index treatment. Patients who did not have a 45-day gap of their index treatment or added adjunct therapy were considered as having ongoing treatment. Time-to-switch and time-to-discontinuation were calculated as time (in days) from the index treatment date to the switch or discontinuation date.

Treatment pattern analysis was conducted among overall $\mathrm{AD}$ patients who initiated $\mathrm{AD}$ treatment with monotherapy. As a sensitivity analysis, treatment patterns analysis was assessed among patients in two subset groups, specifically a) patients who were alive at the end of the follow-up period and b) patients who were alive and living in the community during the study period, defined as no linked MDS data information during the study period.

For the overall population and the two subset groups in the sensitivity analysis, treatment patterns were examined 1) for the entire 

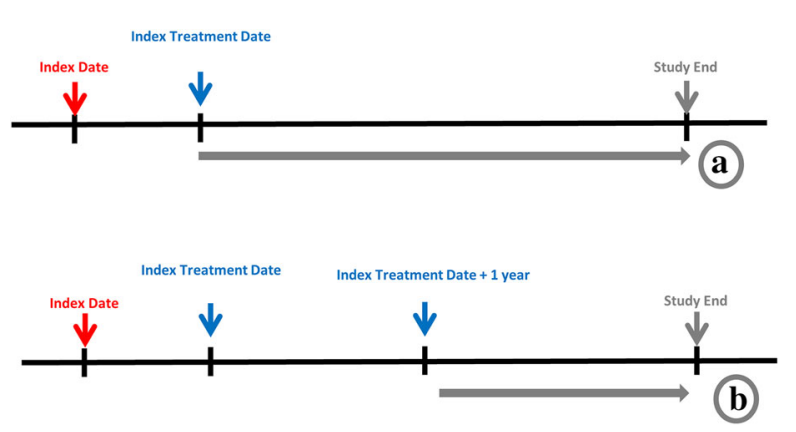

Fig. 2 Treatment pattern analysis. a Treatment patterns were examined for the entire follow-up period. b Treatment patterns were examined after the subsequent 1 year following initiation of $\mathrm{AD}$ treatment

follow-up period and 2) after the subsequent 1 year following initiation of $\mathrm{AD}$ treatment among patients with a $\geq 1$-year follow-up after treatment and ongoing treatment of an index drug after 1 year (Fig. 2).

Patients with one fill of treatment were examined and defined as "primary non-persistence patients". To measure treatment adherence, the medication possession ratio (MPR) was calculated for each index treatment among patients with $\geq 2$ fills for the index medication (i.e., AChEI and memantine) prior to the earliest of run-out date of index treatment or switch. The numerator was the total prescription days of supply of the index drug. The denominator was calculated using the date of last prescription minus date of first prescription plus days of supply of last prescription.

\section{Statistical Analysis}

Descriptive analyses were conducted for all baseline and treatment outcome variables. Number and percentage of patients were calculated for dichotomous and polychotomous variables. Means and standard deviations (SDs) were provided for continuous variables.

Time-to-switch and time-to-discontinuation between donepezil, rivastigmine, galantamine, and memantine were estimated using Kaplan-Meier curves. To examine time-to-switch, patients with ongoing treatment were censored at the time of follow-up end date, patients who discontinued treatment were censored at the index treatment run-out date plus 45 days, and those with retreatment were censored at the index treatment run-out date plus 45 days. To examine time-to-discontinuation, patients with ongoing treatment were censored as of the follow-up end date, patients who switched were censored at the switch date, and patients with retreatment were censored at the retreatment date. Patients who died were censored at the end of the follow-up period.

\section{RESULTS}

After applying the selection criteria, we identified 9812 patients newly diagnosed with $\mathrm{AD}$ between 2008 and 2012. Of those, 56.7\% $(n=5567)$ were treated with anti-dementia treatment after index AD diagnosis, of whom 5200 patients initiated monotherapy and were included in the treatment pattern analysis (Fig. 3).

On average, newly diagnosed $\mathrm{AD}$ patients received monotherapy anti-dementia medication 136 days (4.5 months) after diagnosis (median: 39 days). Monotherapy-treated $\mathrm{AD}$ patients received donepezil (67.8\%),

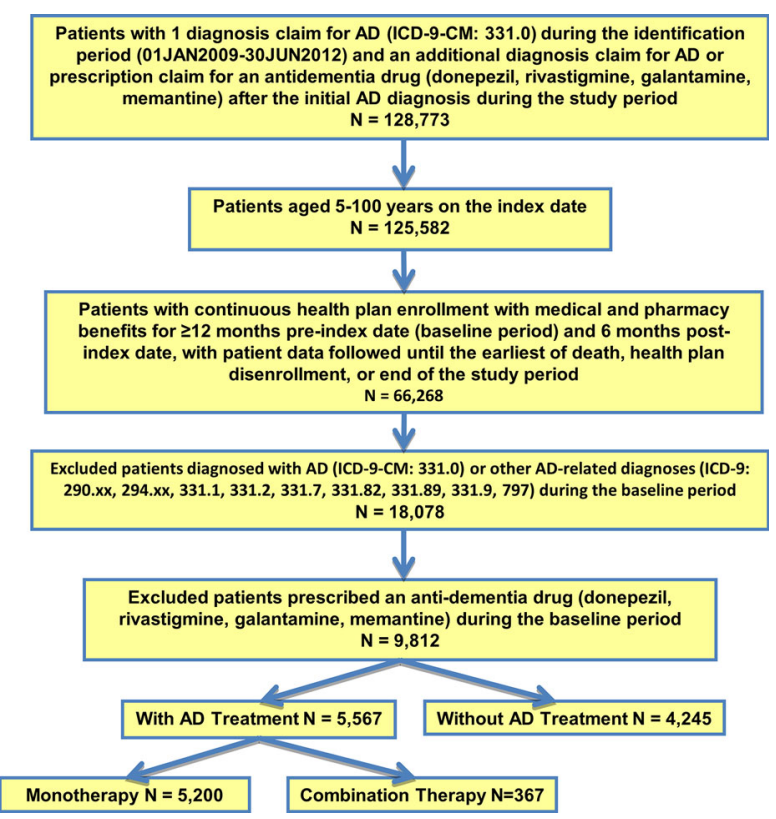

Fig. 3 Patient selection flow chart. $A D$ Alzheimer's disease, ICD-9-CM International Classification of Diseases, 9th Revision, Clinical Modification 
memantine $(15.6 \%)$, rivastigmine $(14.6 \%)$, and galantamine $(1.9 \%)$ as their first-line treatment.

\section{Baseline Characteristics}

The mean age of the study sample was 81.7 years, and the majority of the patients were female $(73.8 \%)$. Approximately $78 \%$ of the population was white and $10.2 \%$ was black (Table 1). The mean CCI was 3.3 and the most common baseline comorbidities were hypertension (75.4\%), dyslipidemia (31.2\%), and diabetes (33.6\%). The most commonly used concomitant medications during the 1-year baseline period were antihypertensives (77.5\%), treatments for dyslipidemia (49.2\%), and opioids (39.6\%; Table 1). Baseline CPS and ADL scores among study patients are presented in Supplementary Table 1.

\section{Treatment Patterns}

Treatment patterns were calculated during the entire follow-up period as well as after 1 year of index treatment for patients who had $a \geq 1$-year follow-up and had treatment of an index drug after 1 year of treatment initiation (Table 2). The entire follow-up time after treatment initiation averaged 659.7 days.

Among patients who initiated monotherapy with an AChEI or memantine, 2684 patients $(51.6 \%)$ had ongoing index treatment or were retreated with index treatment after a 45-day gap. Additionally, 1126 patients (21.7\%) discontinued their index AD treatment and received no additional $\mathrm{AD}$ treatment. The highest rate of discontinuation was observed in patients treated with galantamine $(27.5 \%)$, and the lowest discontinuation rate was observed in patients treated initially with memantine monotherapy (19.0\%). Of those who initiated monotherapy treatment with an AChEI $(N=4386), 11.1 \%$ received adjunct therapy in the follow-up period. For AChEI users, patients who initiated with galantamine had a relatively high rate of switching to another AChEI (8.2\%). Switch rates to memantine from an AChEI were relatively low and the highest rate was for patients who started treatment with
Table 1 Baseline characteristics among incident AD patients with monotherapy

\begin{tabular}{|c|c|c|}
\hline & \multirow{2}{*}{\multicolumn{2}{|c|}{$\begin{array}{l}\text { AD patients with } \\
\text { monotherapy }\end{array}$}} \\
\hline & & \\
\hline & $N /$ mean & $\% / S D$ \\
\hline Age (mean) & 81.70 & 7.03 \\
\hline \multicolumn{3}{|l|}{ Age group } \\
\hline $65-74$ & 872 & $16.77 \%$ \\
\hline $75-84$ & 2418 & $46.50 \%$ \\
\hline $85-94$ & 1763 & $33.90 \%$ \\
\hline $95-100$ & 147 & $2.83 \%$ \\
\hline \multicolumn{3}{|l|}{ Race } \\
\hline White & 4077 & $78.40 \%$ \\
\hline Black & 533 & $10.25 \%$ \\
\hline Hispanic & 307 & $5.90 \%$ \\
\hline Asian & 190 & $3.65 \%$ \\
\hline Native American & 21 & $0.40 \%$ \\
\hline Other & 64 & $1.23 \%$ \\
\hline Unknown & 8 & $0.15 \%$ \\
\hline
\end{tabular}

Gender

$\begin{array}{lll}\text { Male } & 1360 & 26.15 \% \\ \text { Female } & 3840 & 73.85 \%\end{array}$

Geographic location

Northeast 965

$18.56 \%$

North Central

$20.69 \%$

South

West

824

$15.85 \%$

Unknown

52

$1.00 \%$

Baseline comorbidity index

Charlson Comorbidity

Index score

Individual comorbidities

Myocardial infarction

269

$5.17 \%$

Congestive heart failure

885

$17.02 \%$

Peripheral vascular disease 
Table 1 continued

\begin{tabular}{|c|c|c|}
\hline & \multirow{2}{*}{\multicolumn{2}{|c|}{$\begin{array}{l}\text { AD patients with } \\
\text { monotherapy }\end{array}$}} \\
\hline & & \\
\hline & $N /$ mean & $\% / S D$ \\
\hline Subarachnoid hemorrhage & 16 & $0.31 \%$ \\
\hline Intracerebral hemorrhage & 26 & $0.50 \%$ \\
\hline $\begin{array}{l}\text { Other and unspecified } \\
\text { intracranial hemorrhage }\end{array}$ & 42 & $0.81 \%$ \\
\hline $\begin{array}{l}\text { Occlusion and stenosis of } \\
\text { pre-cerebral arteries }\end{array}$ & 531 & $10.21 \%$ \\
\hline $\begin{array}{l}\text { Occlusion of cerebral } \\
\text { arteries }\end{array}$ & 314 & $6.04 \%$ \\
\hline $\begin{array}{l}\text { Transient cerebral } \\
\text { ischemia }\end{array}$ & 329 & $6.33 \%$ \\
\hline $\begin{array}{l}\text { Acute, but ill-defined, } \\
\text { cerebrovascular disease }\end{array}$ & 321 & $6.17 \%$ \\
\hline $\begin{array}{l}\text { Other and ill-defined } \\
\text { cerebrovascular disease }\end{array}$ & 353 & $6.79 \%$ \\
\hline $\begin{array}{l}\text { Chronic pulmonary } \\
\text { disease }\end{array}$ & 1273 & $24.48 \%$ \\
\hline Rheumatologic disease & 270 & $5.19 \%$ \\
\hline Peptic ulcer disease & 113 & $2.17 \%$ \\
\hline Mild liver disease & 16 & $0.31 \%$ \\
\hline Hemiplegia or paraplegia & 66 & $1.27 \%$ \\
\hline $\begin{array}{l}\text { Moderate or severe renal } \\
\text { disease }\end{array}$ & 614 & $11.81 \%$ \\
\hline Diabetes & 1749 & $33.63 \%$ \\
\hline Malignancy & 622 & $11.96 \%$ \\
\hline $\begin{array}{l}\text { Moderate or severe liver } \\
\text { disease }\end{array}$ & 7 & $0.13 \%$ \\
\hline AIDS & 3 & $0.06 \%$ \\
\hline Hypertension & 3923 & $75.44 \%$ \\
\hline Depression & 1031 & $19.83 \%$ \\
\hline Skin ulcers/cellulitis & 584 & $11.23 \%$ \\
\hline Parkinson's disease & 193 & $3.71 \%$ \\
\hline Epilepsy & 214 & $4.12 \%$ \\
\hline
\end{tabular}

Table 1 continued

\begin{tabular}{|c|c|c|}
\hline & \multirow{2}{*}{\multicolumn{2}{|c|}{$\begin{array}{l}\text { AD patients with } \\
\text { monotherapy }^{\mathrm{a}} \\
(N=5200)\end{array}$}} \\
\hline & & \\
\hline & $N /$ mean & $\% / S D$ \\
\hline Anxiety disorders & 165 & $3.17 \%$ \\
\hline Psychotic disorders & 132 & $2.54 \%$ \\
\hline Other mood disorder & 717 & $13.79 \%$ \\
\hline Pneumonia & 320 & $6.15 \%$ \\
\hline Dyslipidemia & 3183 & $61.21 \%$ \\
\hline $\begin{array}{l}\text { Benign prostatic } \\
\text { hyperplasia }\end{array}$ & 466 & $8.96 \%$ \\
\hline Urinary tract infection & 1341 & $25.79 \%$ \\
\hline Septicemia & 92 & $1.77 \%$ \\
\hline $\begin{array}{l}\text { Hip fracture and other } \\
\text { fractures }\end{array}$ & 608 & $11.69 \%$ \\
\hline Other injuries & 1528 & $29.38 \%$ \\
\hline Stroke & 971 & $18.67 \%$ \\
\hline \multicolumn{3}{|c|}{ Baseline concomitant medications } \\
\hline Antipsychotics & 395 & $7.60 \%$ \\
\hline Antidepressants & 1802 & $34.65 \%$ \\
\hline Hypnotics & 825 & $15.87 \%$ \\
\hline Anticoagulants & 662 & $12.73 \%$ \\
\hline Antiplatelets & 741 & $14.25 \%$ \\
\hline NSAIDs & 1230 & $23.65 \%$ \\
\hline Antihistamine & 634 & $12.19 \%$ \\
\hline Prostate-anticholinergic & 984 & $18.92 \%$ \\
\hline Antidiabetics & 1199 & $23.06 \%$ \\
\hline Antihypertensives & 4032 & $77.54 \%$ \\
\hline Antiepileptics & 742 & $14.27 \%$ \\
\hline Antiemetic neuroleptics & 453 & $8.71 \%$ \\
\hline Opioids & 2058 & $39.58 \%$ \\
\hline Hormones & 217 & $4.17 \%$ \\
\hline Stimulants & 17 & $0.33 \%$ \\
\hline For dyslipidemia & 2561 & $49.25 \%$ \\
\hline
\end{tabular}


Table 1 continued

\begin{tabular}{lll}
\hline & \multicolumn{2}{l}{$\begin{array}{l}\text { AD patients with } \\
\text { monotherapy }\end{array}$} \\
\cline { 2 - 3 } & \multicolumn{2}{l}{$(N=\mathbf{5 2 0 0})$} \\
\cline { 2 - 3 } & N/mean & $\% /$ SD \\
\hline For Parkinson's disease & 253 & $4.87 \%$ \\
Anxiolytics & 67 & $1.29 \%$ \\
\hline
\end{tabular}

$A D$ Alzheimer's disease, NSAIDs Nonsteroidal anti-inflammatory drugs, $S D$ standard deviation

a $N=489$ (9.4\%) monotherapy treated patients had linked MDS data rivastigmine, in which case $4.2 \%$ switched to memantine during the follow-up period. Approximately $25 \%$ of the patients switched treatment and $20 \%$ discontinued treatment about 8 months after index treatment initiation. Differences were observed for time-to-switch among patients prescribed the four anti-dementia drugs. Patients who initiated their treatment with rivastigmine had shorter treatment durations before switching. Similar outcomes were found for time-to-discontinuation among the anti-dementia treatments, while galantamine patients were more likely to discontinue treatment in the first 2 years (Fig. 4).

Table 2 Treatment pattern among incident AD patients with monotherapy

\begin{tabular}{|c|c|c|c|c|c|c|c|}
\hline $\begin{array}{l}\text { Index } \\
\text { treatment }\end{array}$ & $N$ & $\begin{array}{l}\text { Ongoing or } \\
\text { retreated with } \\
\text { same index } \\
\text { drug }\end{array}$ & $\begin{array}{l}\text { Retreated } \\
\text { with other } \\
\text { AD drug }\end{array}$ & Discontinued & $\begin{array}{l}\text { Switch to } \\
\text { any AChEI }\end{array}$ & $\begin{array}{l}\text { Switch to } \\
\text { memantine }\end{array}$ & $\begin{array}{l}\text { Adjunct } \\
\text { therapy with } \\
\text { memantine } \\
\text { and AChEI }\end{array}$ \\
\hline \multicolumn{8}{|c|}{ (a) Treatment pattern during the entire follow-up period } \\
\hline Donepezil & 3527 & $1881(53.33 \%)$ & $231(6.55 \%)$ & $774(21.94 \%)$ & $107(3.03 \%)$ & $130(3.69 \%)$ & $395(11.20 \%)$ \\
\hline Rivastigmine & 761 & $345(45.34 \%)$ & $68(8.94 \%)$ & $170(22.34 \%)$ & $50(6.57 \%)$ & $32(4.20 \%)$ & $83(10.91 \%)$ \\
\hline Galantamine & 98 & $39(39.80 \%)$ & $15(15.31 \%)$ & $27(27.55 \%)$ & $8(8.16 \%)$ & $1(1.02 \%)$ & $7(7.14 \%)$ \\
\hline Memantine & 814 & $419(51.47 \%)$ & $66(8.11 \%)$ & $155(19.04 \%)$ & $44(5.41 \%)$ & & $130(15.97 \%)$ \\
\hline $\begin{array}{l}\text { Any } \\
\text { anti-dementia } \\
\text { drug }^{\mathrm{a}}\end{array}$ & 5200 & $2684(51.62 \%)$ & $380(7.31 \%)$ & $1126(21.65 \%)$ & & & $615(11.83 \%)$ \\
\hline Any $\mathrm{AChEI}^{\mathrm{b}}$ & 4386 & $2265(51.64 \%)$ & $314(7.16 \%)$ & $971(22.14 \%)$ & & & $485(11.06 \%)$ \\
\hline \multicolumn{8}{|c|}{ (b) Treatment pattern after the subsequent 1 year following initiation of $\mathrm{AD}$ treatment } \\
\hline Donepezil & 911 & $692(75.96 \%)$ & $14(1.54 \%)$ & $97(10.65 \%)$ & $9(0.99 \%)$ & $12(1.32 \%)$ & $86(9.44 \%)$ \\
\hline Rivastigmine & 129 & $88(68.22 \%)$ & $8(6.20 \%)$ & $10(7.75 \%)$ & $1(0.78 \%)$ & $5(3.88 \%)$ & $14(10.85 \%)$ \\
\hline Galantamine & 19 & $15(78.95 \%)$ & $2(10.53 \%)$ & $0(0.00 \%)$ & $0(0.00 \%)$ & $1(5.26 \%)$ & $1(5.26 \%)$ \\
\hline Memantine & 193 & $151(78.24 \%)$ & $3(1.55 \%)$ & $21(10.88 \%)$ & $6(3.11 \%)$ & & $12(6.22 \%)$ \\
\hline $\begin{array}{l}\text { Any } \\
\text { anti-dementia } \\
\text { drug }^{\mathrm{a}}\end{array}$ & 1252 & $946(75.56 \%)$ & $27(2.16 \%)$ & $128(10.22 \%)$ & & & $113(9.03 \%)$ \\
\hline Any AChEI** & 1059 & 795 (75.07\%) & $24(2.27 \%)$ & $107(10.10 \%)$ & & & $101(9.54 \%)$ \\
\hline
\end{tabular}

AChEI Acetylcholinesterase inhibitors, AD Alzheimer's disease

a Any anti-dementia: donepezil, rivastigmine, galantamine, and memantine

b Any AChEI: donepezil, rivastigmine, and galantamine 

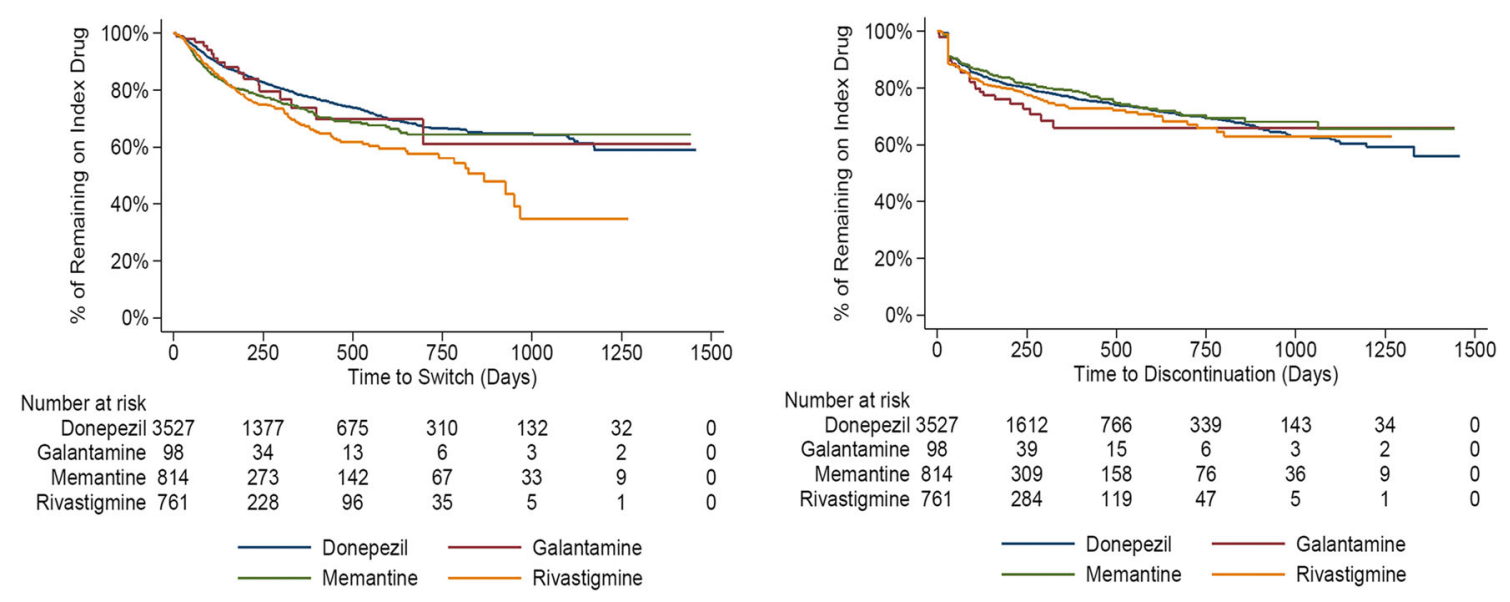

Fig. 4 Kaplan-Meier curve for time-to-switch and time-to-discontinuation among incident Alzheimer's disease patients with monotherapy

A total of 1252 patients had a $\geq 1$-year follow-up and had treatment of index drug after 1 year of treatment initiation, with an average of 833.5 days of follow-up time after treatment initiation. Among patients who started monotherapy treatment with AChEI or memantine, the majority of patients were more likely to continue on treatment after 1 year of therapy. $75.6 \%$ of patients stayed on their index medicine throughout the observation period, and $10.2 \%$ discontinued $\mathrm{AD}$ treatment at some point after the 1 year and had no subsequent $\mathrm{AD}$ treatment. Of those who initiated monotherapy treatment with an AChEI $(N=632), 9.5 \%$ obtained adjunct therapy with

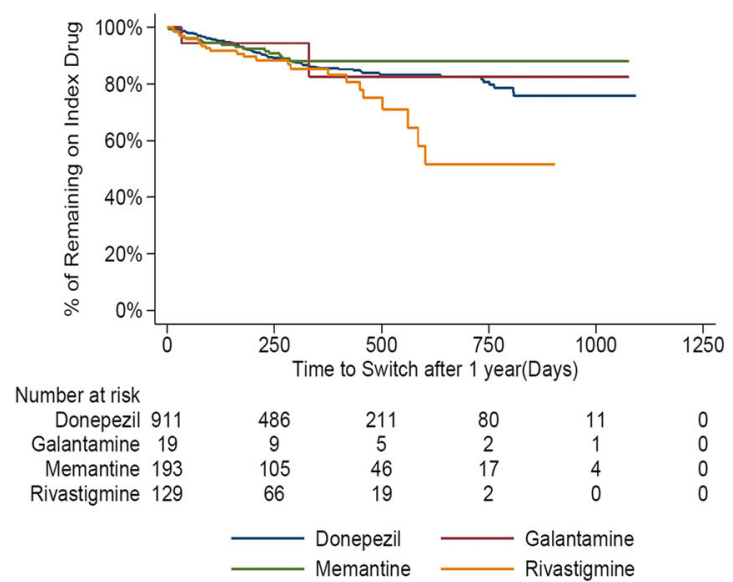

memantine at some point after 1 year. Kaplan-Meier curves for time-to-switch and time-to-discontinuation were consistent and indicated that patients were more likely to remain on index treatment after 1 year of treatment initiation (Fig. 5).

Among those who renewed their index AChEI at least once, the MPR of each index treatment was high, indicating good adherence to anti-dementia medication among newly diagnosed AD patients and that the MPR did not differ significantly among the four study drugs. Adherence rates were 93, 92, 94, and 92\% for donepezil, rivastigmine, galantamine, and memantine, respectively. Of note, the

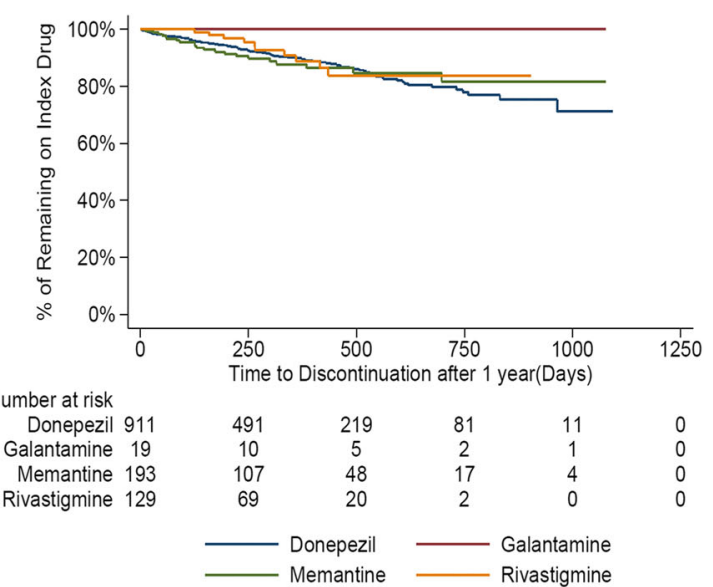

Fig. 5 Kaplan-Meier curve for time-to-switch and time-to-discontinuation after 1 year among incident AD patients with monotherapy 
proportion of patients not renewing their index treatment at least once, also called primary non-adherence, varied across index treatment: $25,40,31$, and $24 \%$ for donepezil, rivastigmine, galantamine, and memantine, respectively.

As compared to the overall AD population, similar treatment pattern results were found in the sensitivity analyses among patients who were alive at the end of the study period and those who were alive residing in the community. Of those who began their monotherapy treatment with an AChEI, 52\% continued index treatment over the follow-up period and 75\% continued their index treatment over the subsequent year (Supplemental Tables 2 \& 3). Additionally, between 20 and 30\% of patients discontinued or switched treatment 8 months after index treatment initiation (Supplement Figs. 1, 2).

\section{DISCUSSION}

A retrospective cohort analysis was conducted to evaluate treatment patterns among newly diagnosed Alzheimer's patients receiving anti-dementia drugs (AChEIs and memantine) after diagnosis for AD using USA Medicare administration claims from 2008 through 2012. Our study used both the Medicare claims and linked MDS datasets to examine the treatment patterns and characteristics of $\mathrm{AD}$ patients in the USA, allowing us to capture more patient and disease characteristics.

Previous studies have shown that non-treatment of $\mathrm{AD}$ may be associated with poorer outcomes [24, 25]. A recent study in Germany found that the majority of incident AD cases did not receive medication in conformity with care guidelines in the year after incidence, which was related to not visiting a specialist, living in urban areas, age, and comorbid conditions [26]. Of the newly diagnosed and treatment-naïve patients identified in this study, approximately $56.7 \%$ received a pharmacologic $\mathrm{AD}$ treatment at some time after diagnosis. A retrospective claims analysis of dementia patients enrolled in Medicare Parts A, B, and D showed a similar treatment rate $(49.3 \%)$ when considering patients who were treated after diagnosis [27].
The current analysis also examined and compared untreated versus treated patients (Supplemental Table 4). Untreated patients tend to be older, have greater disease comorbidity, and worsened AD-related disease severity scores compared to treated patients. This study did not attempt to define the causal direction of this relationship. Evidence from long-term observational controlled studies supports the early initiation and persistent exposure to AD therapy for delaying nursing home admission and significantly decelerating rates of cognitive and functional impairment [10]. For moderate-to-severe $\mathrm{AD}$ patients who are no longer responding to lower doses, therapeutic trials of higher dose AChEIs in combination with memantine are recommended [10]. Side-effects of AChEI therapy are largely mild and gastrointestinal but can lead to significant morbidity in patients with advanced disease [10]. Patients who initiated treatment with a monotherapy were mostly between the ages of 75-84 and had more severe comorbidities but had similar AD-related disease severity scores to those who were treated with a combination therapy (results not presented). It is important to note that the Medicare database lacks information on disease stage which may have a significant impact on treatment pattern.

Several studies have examined the treatment patterns of anti-dementia drugs among $\mathrm{AD}$ patients. A retrospective cohort study among 299 AD patients from January 2000 through March 2005 showed that donepezil (mean treatment duration: 83.3 weeks, median persistence time: 70.3 weeks; $95 \%$ CI: 49.8-90.7) had a significantly higher persistence compared to rivastigmine (mean treatment duration: 76.6 weeks, median persistence time: 56.1 weeks; 95\% CI: 36.1-76.2), galantamine (mean treatment duration: 65.8 weeks, median persistence time: 56.7 weeks; $95 \% \quad \mathrm{CI}$ : 41.1-72.3), and memantine (mean treatment duration: 60.9 weeks, median persistence time: 52.1 weeks; 95\% CI: 35.2-69.1) [28].

Our study demonstrated the same trend of donepezil having the highest percentage of patients continuing treatment. Another retrospective claims analysis among 3091 AD patients prescribed rivastigmine, donepezil, 
galantamine, or memantine found that $40 \%$ of the patients discontinued treatment after a mean duration of 119 (79.8) days [17]. This number is higher than what we observed, with a discontinuation rate of approximately 20\% during the follow-up period in this study. Since patients were followed in the current analysis until health plan disenrollment, death, or study end, whichever occurred first, the discontinuation rate may have been confounded by different follow-up lengths. Additionally, the patients with the higher discontinuation rates were Medicare Advantage patients studied in an era of higher treatment costs and may have been treated prior to diagnosis.

Mucha et al. assessed the differences in various measures of medication adherence with donepezil, rivastigmine, and galantamine [19]. The persistence rate of use with the initial AChEI at 12 months was $36.4 \%$ for donepezil, $36.3 \%$ for rivastigmine, and $32.0 \%$ for galantamine; in our study, the 12-month persistent use was also higher for donepezil (35.3\%, $911 / 2582)$ than for galantamine $(24.4 \%, 19 / 78)$ or rivastigmine $(23.3 \%, 129 / 553)$. The prevalence use of AChEI in this study was lower compared to the results reported in the Mucha et al. study (2008) and may be due to (1) different study samples (in fact, Mucha et al. included pharmacy and medical claims from the Medicare Supplemental database whereas this study utilized Medicare claims) and (2) the inclusion of previously treated $\mathrm{AD}$ patients (while we excluded these patients). In addition, Mucha et al.'s adherence rates (approximately $70 \%$ for AChEIs) were lower compared to our adherence rates (around 90\% for AChEI or memantine). The MPR in the current analysis was assessed among patients with two fills during the entire study follow-up (end of 2012 or death) and before patients discontinued or switched medication. MPR rates would have dropped if primary non-adherent patients were included in the MPR calculation.

A retrospective analysis using the MarketScan database from 1999 to 2002 showed that $47 \%$ of patients newly treated with rivastigmine or donepezil continuously used the medications with a mean duration around 235 days, and patients were more likely to discontinue or switch treatment if prior central nervous system medications were prescribed [24]. The results of our study suggest that around $20 \%$ of the sample had a treatment change (switch or discontinuation) 8 months after initiation of the index treatment.

This study found that when patients continued on the same AD treatment after 1 year, they were more likely to remain on their $\mathrm{AD}$ treatment. This was most evident among patients prescribed donepezil for 1 year, and $76.0 \%$ continued their index drug after 1 year of treatment. The results may suggest that once $\mathrm{AD}$ is treated, persistence to treatment is valued by the physician and/or patient. However, our assumption is limited to the extent of the study observation period. It is important to note that this study is mainly descriptive. Multivariable analysis, adjusting for patients' clinical and demographic characteristics, was not undertaken. However, to assess the potential magnitude of confounding variables, sensitivity analysis was performed excluding deceased patients and patients living in a nursing home (proxy for health status). Deceased patients or patients who resided in a nursing facility were assumed to have more comorbidities than the general patient population. However, treatment patterns were found to be similar across the three population sets in our study.

As our findings (which remained robust in sensitivity) were not able to provide important insights regarding the relative determinants of persistence with AChEI and memantine drugs, the explanatory factors for utilization patterns remain uncertain and require further investigation. A population-based, real-world Canadian study of 1000 patients (mean age 80 years) suggested there is a greater persistence with AChEI therapy for those aged 75-79 (vs. <70), and comorbidity was shown to influence persistence with AChEI therapy as evidenced by a higher Chronic Disease Score [29].

This study included a comprehensive description of the treatment patterns for the most commonly prescribed anti-dementia drugs (AChEIs and memantine). A strict and more robust inclusion criterion was implemented to capture only newly diagnosed AD patients. By way of the study design, we also confirmed AD 
by requiring an additional $\mathrm{AD}$ diagnosis after the initial $\mathrm{AD}$ diagnosis. Treatment pattern results were presented for the entire follow-up period and after the first year of treatment, which showed the timing of switch, discontinuation, and retreatment for initial medications among newly diagnosed AD patients.

The findings should be considered in light of several other limitations. Given the observational nature of the study, only associations can be drawn without causal linkage. Additionally, retrospective claims analyses are subject to coding errors or incorrectly entered diagnoses that were primarily coded for administrative processing rather than clinical completeness. Finally, variables such as $\mathrm{AD}$ duration, over-the-counter medication use, and patient health behavior are not captured and, therefore, could not be measured. Ultimately, many of the estimates may be biased due to residual confounding.

Although Medicare data have been widely used in health outcome research studies, several additional limitations have to be considered. Our study included fee-for-service patients who enrolled in Medicare Part A and B. Medicare Part C, also known as Medicare Advantage, was not used in this study, which may limit the generalizability of the study results.

At the time of this analysis, the International Classification of Diseases, 10th Revision (ICD-10) was not implemented yet. The eventual shift from ICD-9 to ICD-10 codes will likely improve results and quality of care since specific coding that more accurately depicts patients' actual conditions will allow for better and effective disease management.

Due to the nature of the dataset, no clinical measures were obtained for this study, introducing the possibility of confounding. For example, no information on disease severity was available, which may alter the treatment pattern.

\section{CONCLUSION}

This retrospective study examined treatment patterns for anti-dementia drugs (memantine and AChEIs) among newly diagnosed $\mathrm{AD}$ patients in the USA Medicare system. In this USA Medicare population, approximately half of the patients who were treated with AChEI continued the index treatment, and more than $20 \%$ discontinued and were untreated afterwards. Patients who initiated treatment with AChEIs or memantine were more likely to continue their treatment if they were persistent on index treatment for the first year. Further analyses will examine treatment patterns by patient demographic and clinical characteristics.

\section{ACKNOWLEDGEMENTS}

Sponsorship for this study and article processing charges was funded by Lundbeck and Otsuka. Lin Xie, Yeuxi Wang, Furaha Kariburyo, and Onur Baser had full access to all of the data in the study and take responsibility for the integrity of the data and the accuracy of the analysis. Editorial assistance in the preparation of this manuscript was provided by Chris Haddlesey of STATinMED Research, Inc. Support for this assistance was funded by Lundbeck and Otsuka. All named authors meet the International Committee of Medical Journal Editors (ICMJE) criteria for authorship for this manuscript, take responsibility for the integrity of the work as a whole, and have given final approval for the version to be published.

Disclosures. Nawal Bent-Ennakhil is an employee of Lundbeck and completed the planning, study design, analysis, and interpretation of the data as part of that employment. Florence Coste is an employee of Lundbeck and completed the planning, study design, analysis, and interpretation of the data as part of that employment. Ann Hartry is an employee of Lundbeck and completed the planning, study design, analysis, and interpretation of the data as part of that employment. Lin Xie is an employee of STATinMED Research, Inc., a paid consultant to Lundbeck. Yuexi Wang is an employee of STATinMED Research, Inc., a paid consultant to Lundbeck. Furaha Kariburyo is an employee of STATinMED Research, Inc., a paid 
consultant to Lundbeck. Onur Baser is an employee of STATinMED Research, Inc., a paid consultant to Lundbeck. Myrlene Sanon Aigbogun is an employee at Otsuka. Peter Neumann has nothing to disclose. Howard Fillit received consulting fees from Lundbeck.

Compliance with Ethical Standards. This article does not contain any new studies with human or animal subjects performed by any of the authors. Since the core study proposed herein was for research purpose only and did not include any individual identifiable data, institutional review board (IRB) exemption was approved for this study. The security of the data meets the requirements of the Health Insurance Portability and Accountability Act (HIPAA) of 1996.

Data Availability. The datasets during and/ or analyzed during the current study are available from the corresponding author on reasonable request.

Open Access. This article is distributed under the terms of the Creative Commons Attribution-NonCommercial 4.0 International License (http://creativecommons.org/licenses/ by-nc/4.0/), which permits any noncommercial use, distribution, and reproduction in any medium, provided you give appropriate credit to the original author(s) and the source, provide a link to the Creative Commons license, and indicate if changes were made.

\section{REFERENCES}

1. Association Alzheimer's. 2015 Alzheimer's disease facts and figures. Alzheimers Dement. 2015;11(3):332-84.

2. Murphy SL, Xu J, Kochanek KD. Deaths: final data for 2010. Natl Vital Stat Rep. 2013;61(4):1-117.

3. Murray CJ, Atkinson C, Bhalla K, et al. The state of US health, 1990-2010: burden of diseases, injuries, and risk factors. JAMA. 2013;310(6):591-608.

4. Birks JS. Cholinesterase inhibitors for Alzheimer's disease. Cochrane Database Syst Rev. 2006;1:CD005593.
5. Farlow MR. Do cholinesterase inhibitors slow progression of Alzheimer's disease? Int J Clin Pract Suppl. 2002;127:37-44.

6. Kaduszkiewicz H, Zimmermann T, Beck-Bornholdt $\mathrm{HP}$, van den Bussche $\mathrm{H}$. Cholinesterase inhibitors for patients with Alzheimer's disease: systematic review of randomised clinical trials. BMJ. 2005;331(7512):321-7.

7. Trinh NH, Hoblyn J, Mohanty S, Yaffe K. Efficacy of cholinesterase inhibitors in the treatment of neuropsychiatric symptoms and functional impairment in Alzheimer disease: a meta-analysis. JAMA. 2003;289(2):210-6.

8. Zhu CW, Livote EE, Scarmeas N, et al. Long-term associations between cholinesterase inhibitors and memantine use and health outcomes among patients with Alzheimer's disease. Alzheimers Dement. 2013;9(6):733-40.

9. Lleó A. Current therapeutic options for Alzheimer's disease. Curr Genomics. 2007;8(8):550-8.

10. Deardorff WJ, Feen E, Grossberg GT. The use of cholinesterase inhibitors across all stages of Alzheimer's disease. Drugs Aging. 2015;32(7):537-47.

11. Peskind ER, Potkin SG, Pomara N, et al. Memantine treatment in mild to moderate Alzheimer disease: a 24-week randomized, controlled trial. Am J Geriatr Psychiatry. 2006;14(8):704-15.

12. Thomas SJ, Grossberg GT. Memantine: a review of studies into its safety and efficacy in treating Alzheimer's disease and other dementias. Clin Interv Aging. 2009;4:367-77.

13. Seltzer B. Cholinesterase inhibitors in the clinical management of Alzheimer's disease: importance of early and persistent treatment. J Int Med Res. 2006;34(4):339-47.

14. Sano M, Amatniek J, Feely M, et al. Undertreatment of patients with Alzheimer's disease in an elderly United States population. Alzheimers Dement. 2005;1(2):136-44.

15. Auriacombe S, Pere JJ, Loria-Kanza Y, Vellas B. Efficacy and safety of rivastigmine in patients with Alzheimer's disease who failed to benefit from treatment with donepezil. Curr Med Res Opin. 2002;18(3):129-38.

16. Lazzeroni LC, Halbauer JD, Ashford JW, et al. Memantine is associated with longer survival than donepezil in a Veterans Affairs prescription database, 1997 to 2008. J Alzheimers Dis. 2013;36(4):791-8.

17. Borah B, Sacco P, Zarotsky V. Predictors of adherence among Alzheimer's disease patients receiving 
oral therapy. Curr Med Res Opin. 2010;26(8):1957-65.

18. Scharre DW, Vekeman F, Lefebvre P, Mody-Patel N, Kahler KH, Duh MS. Use of antipsychotic drugs in patients with Alzheimer's disease treated with rivastigmine versus donepezil: a retrospective, parallel-cohort, hypothesis-generating study. Drugs Aging. 2010;27(11):903-13.

19. Mucha L, Shaohung S, Cuffel B, McRae T, Mark TL, Del Valle M. Comparison of cholinesterase inhibitor utilization patterns and associated health care costs in Alzheimer's disease. J Manag Care Pharm. 2008;14(5):451-61.

20. Brewer L, Bennett K, McGreevy C, Williams D. A population-based study of dosing and persistence with anti-dementia medications. Eur J Clin Pharmacol. 2013;69(7):1467-75.

21. Bohlken J, Weber S, Rapp MA, Kostev K. Continuous treatment with antidementia drugs in Germany 2003-2013: a retrospective database analysis. Int Psychogeriatr. 2015;27(8):1335-42.

22. Morris JN, Fries BE, Mehr DR, et al. MDS cognitive performance scale. J Gerontol. 1994;49(4):M174-82.

23. Morris JN, Fries BE, Morris SA. Scaling ADLs within the MDS. J Gerontol A Biol Sci Med Sci. 1999;54(11):M546-53.
24. Winblad B, Wimo A, Engedal K, et al. 3-year study of donepezil therapy in Alzheimer's disease: effects of early and continuous therapy. Dement Geriatr Cogn Disord. 2006;21(5-6):353-63.

25. Geldmacher DS, Frolich L, Doody RS, et al. Realistic expectations for treatment success in Alzheimer's disease. J Nutr Health Aging. 2006;10(5):417-29.

26. van den Bussche H, Kaduszkiewicz H, Koller D, et al. Antidementia drug prescription sources and patterns after the diagnosis of dementia in Germany: results of a claims data-based 1-year follow-up. Int Clin Psychopharmacol. 2011;26(4):225-31.

27. Koller D, Hua T, Bynum JP. Treatment patterns with antidementia drugs in the United States: medicare cohort study. J Am Geriatr Soc. 2016;64(8):1540-8.

28. Sicras-Mainar A, Vergara J, Leon-Colombo T, Febrer L, Rejas-Gutierrez J. Retrospective comparative analysis of antidementia medication persistence patterns in Spanish Alzheimer's disease patients treated with donepezil, rivastigmine, galantamine and memantine. Rev Neurol. 2006;43(8):449-53.

29. Amuah JE, Hogan DB, Eliasziw M, et al. Persistence with cholinesterase inhibitor therapy in a population-based cohort of patients with Alzheimer's disease. Pharmacoepidemiol Drug Saf. 2010;19(7):670-9. 